\title{
Teratokartzinometatik eratorritako zelula-lerro neuronalen (NT2N) transplantea: istripu zerebrobaskularra izandako gaixo kronikoentzako estrategia terapeutiko berria
}

\author{
(Neural cell lines derived from teratocarcinoma (NT2N) \\ as graft source for cell transplantation: \\ a new therapeutic strategy for chronic stroke patients)
}

\author{
Amaia Isasti*1, Imanol Gonzalez-Burguera ${ }^{2}$, Leire Borrega ${ }^{1}$, \\ Miquel Saumell ${ }^{1}$, Sergio Barrondo ${ }^{1,3}$, Joan Sallés ${ }^{1,3}$, Gontzal García del Caño $o^{2}$, \\ Maider López de Jesús ${ }^{1,3}$ \\ ${ }^{1}$ Farmakologia Saila, Farmazia Fakultatea (UPV/EHU) \\ ${ }^{2}$ Neurozientzia Saila, Farmazia Fakultatea (UPV/EHU) \\ ${ }^{3}$ CIBERSAM. Centro de Investigación Biomédica en Red de Salud Mental
}

\begin{abstract}
LABURPENA: Gaur egun, istripu zerebrobaskularra (IZB) mundu osoan bigarren heriotza-kausa eta ezgaitasunen hirugarren eragilea da. IZB, garuneko zirkulazioaren bat-bateko asaldura da, non, neuronen galera baten ondorioz, aldi baterako edo betirako garunaren eskualde jakin baten funtzioa eraldatzen den. Hortaz, praktika klinikoan, prebentzioan lan egiteaz gain, ezinbestekoa da funtzio neurologikoen galeraren oinarrian dagoen neuronen heriotzaren kontra zuzendutako tratamendu eraginkorrak izatea. Tamalez, gaur egun erabiltzen diren estrategia terapeutikoen eraginkortasuna mugatua da, eta, kasu gehienetan, IZB izandako pazienteek ez dute bizi-kalitate egokia berreskuratzen. Artikulu honetan, gaixoen ezgaitasunaren arrazoia den neuronen galerari aurre egiteko zelula hauen ordezkapena itu duen terapia zelularra aurkezten da. Zehazki, Ntera2/D1 edo NT2 deituriko zelula-lerrotik eratorritako zelula neuronalen (NT2N) transplantean sakontzen dugu, IZB izandako gaixoetan estrategia berri bezala eskainiko lituzkeen abantailak eta gaur egun arte egindako entsegu pre-klinikoetan zein klinikoetan frogatutako segurtasuna eta eraginkortasuna aztertuz.
\end{abstract}

HITZ GAKOAK: Istripu zerebrobaskularra, Terapia zelularra, Ntera2/D1 zelulak, Zelula neuronalen transplantea.

\begin{abstract}
Currently, Cerebrovascular accident (CVA) also known as stroke, is the third leading cause of disability and death worldwide. CVA is a sudden alteration of cerebral circulation, which results in neural cell death and consequently a temporary or permanent loss in certain neuronal functions. Therefore, in addition to working on prevention, in clinical practice is essential to have effective treatments aimed at avoiding neuronal dead. Unfortunately, the efficacy of the currently used therapeutic strategies is limited and, in most cases, patients suffering from stroke do not recover an adequate quality of life. This article presents cell therapy as a future alternative of interest in the treatment of chronic patients of CVA. This new therapy aims to replace the lost neuronal cells that are the main cause of disability in patients. Specifically, the review article presents recent progress on the use of teratocarcinoma-derived Ntera2/D1 neuronlike cells (NT2N cells), as graft source for cell transplantation in stroke, discussing the safety and efficacy demonstrated by preclinical and clinical trials made to date.
\end{abstract}

KEYWORDS: Cerebrovascular accident, Cell therapy, Ntera2/D1 cells, Neuronlike cell transplantation.

\footnotetext{
* Harremanetan jartzeko / Corresponding author: Amaia Isasti. Farmakologia Saila, Farmazia Fakultatea. (UPV/EHU), Unibertsitateko ibilbidea 7 (01006 Vitoria-Gasteiz, Araba/Álava, Euskal Herria). - isasti.amaia@gmail.com - https://orcid.org/00000001-6119-2630.

Nola aipatu / How to cite: Isasti, Amaia; Gonzalez-Burguera, Imanol; Borrega, Leire; Saumell, Miquel; Barrondo, Sergio; Sallés, Joan; García del Caño, Gontzal; López de Jesús, Maider (2020). "Teratokartzinometatik eratorritako zelula-lerro neuronalen (NT2N) transplantea: istripu zerebrobaskularra izandako gaixo kronikoentzako estrategia terapeutiko berriaw; Ekaia, 38, 2020, 27-40. (https://doi.org/10.1387/ekaia.21296).
}

Jasoa: 13 abendua, 2019; Onartua: 20 martxoa, 2020.

ISSN 0214-9001 - elSSN 2444-3255 / (C) 2020 UPV/EHU

(c) (i) (0) Obra hau Creative Commons Atribución 4.0 Internacional-en lizentziapean dago 
Amaia Isasti, Imanol Gonzalez-Burguera, Leire Borrega, Miquel Saumell, Sergio Barrondo, Joan Sallés, Gontzal García del Caño, Maider López de Jesús

\section{SARRERA}

Istripu zerebrobaskularra (IZB) edo garuneko hodietako istripua (GHI) azkar garatzen den garunaren galera funtzional akutua da. Gaitz hau, batez ere gaixotasun kardiobaskularren intzidentzia altua duten herrialdeetan, lehen mailako osasun-arazoa bilakatzen ari da [1].

Nerbio Sistema Zentraleko (NSZ) odolaren garraioan sor daitezkeen asalduren ondorioz gertatzen da IZB. Hain zuzen ere, asaldura horiek iskemia-egoerak edo odoljarioak izaten dira: bi eragile horietatik ohikoena iskemia izaten da (\%80a) [2, 3]. IZB egoera batean, hodi-uzkurduraren edo odolbildu baten edo odol-galeraren ondorioz (odoljarioa), oxigenoa eta beharrezkoak diren hainbat mantenugairen fluxua gutxitzen da, eta metabolismo neuronala kaltetzen da. Odoljarioen kasuan, gainera, iskemia egoeretan hain ohikoa ez den garezur barneko presio-igoeraren ondoriozko kalteak eragiten dira [4].

Neuronek homeostasi ionikoari eusteko behar duten oxigeno eta mantenugaien hornidura agortzean gradiente ionikoa galtzen denez, zelula despolarizatu egingo da, eta, besteak beste, neurotransmisore kitzikagarrien (glutamatoa) askapena bultzatuko du. Glutamatoaren askapen masiboak N-metil-d-aspartato hartzailearen (NMDAR) gainaktibazioa eragingo du, «exzitotoxikotasuna» deituriko toxikotasun neuronala eraginez. Exzitotoxikotasuna GluN2B-PSD95-nNOS bidearen aktibazioz gertatzen da. Bide horrek dentsitate postsinaptikoko proteina-95 (PSD-95), NMDAR hartzailea eta Oxido Nitrico Sintasa (NOS) lotzen ditu. Aktibatzean, oxido nitrikoaren sintesia bultzatzen da, heriotza zelularraren erantzulea dena [5].

Heriotza-seinale horiek neuronen egitura funtzionalean asaldurak eragingo dituzte, hala nola, proiekzio neuronalen etendura edo neuronen kaltea. Horrek maila zentralean edo periferikoan behin-betikoak izan daitezkeen lesioak eragin ditzake, eta ondorioz, hainbat funtzio neurologikoren galera [6-8]. Kalte neurologikoa gertatzen den gunearen arabera, asaldura funtzionalak maila oso desberdinetan gerta daitezke $[9,10]$.

\section{IZB-en OHIKO ESTRATEGIA TERAPEUTIKOEN MUGAK}

Gaur egun, IZB izandako gaixoei zuzendutako ohiko estrategia terapeutiko nagusiak bi dira: galdutako funtzio neurologikoen berreskurapena helburu duen errehabilitazioa, eta kaltearen hedapena gutxitzeko helburua duen odol-fluxuaren leheneratzea. Asaldura jasan duen guneak odol-fluxua lehenbailehen berreskuratzeko, IZB iskemikoen kasuan, plasminogenoaren aktibatzaile tisularra (tPA) erabiltzen da zain barneko bidetik. tPA odol-hodietako endotelioan dagoen eta plasminogenoa aktibatzen duen en- 
Teratokartzinometatik eratorritako zelula-lerro neuronalen (NT2N) transplantea: istripu zerebrobaskularra izandako gaixo kronikoentzako estrategia terapeutiko berria

tzima bat da. Plasminogenoa gibelean sintetizatzen den glukoproteina bat da, aktibatzen denean odolbilduak desegiten dituen plasmina bilakatzen dena. Tratamendu horrek IZB iskemikoa jasandako gaixoetan nolabaiteko eraginkortasuna duela frogatu da. Dena dela, tratamendua eraginkorra izateko, ezinbestekoa da tPA-ren administrazioa istripua gertatu eta hurrengo 4.5 orduetan ezartzea. Hori dela eta, paziente gutxi dira tratamendu hau erabil dezaketenak [11-15].

tPAren tratamendu akututik haratago, gaur egungo entsegu kliniko askotan neurobabesean oinarritutako tratamendu berriak aztertzen ari dira $[16,17]$. Aukera terapeutiko berri honen helburua da istripua gertatutako guneetatik hurbilen dauden garun-eremuetan heriotza neuronala saihestea [18]. Estrategia horietako bat «hipotermia neurologiko arina da», non gorputzeko tenperatura $33{ }^{\circ} \mathrm{C}$-tara jaisten den. Tenperaturaren jaitsiera horrekin, bi mekanismo potentzialen bitartez neuronen heriotza gutxituko litzateke. Alde batetik, tenperaturaren gradu-jaitsiera bakoitzeko garun-metabolismoa \%6-7an geldotuko litzateke, eta horrek, zelulen oxigeno beharraren eta eskaeraren arteko erlazioa hobetuko luke. Bestetik, hipotermiaegoeraren ondorioz, garezur barneko presioa gutxituko litzateke. Azken honen mekanismo fisiopatologikoa hodi-uzkurdura baten ondoriozko odolbolumenaren jaitsieran oinarritzen da [19].

Azkenik, neurobabesean oinarritutako beste aukera terapeutikoa da glutamatoaren NMDA hartzaileek (NMDAR) bideratzen duten eszitotoxikotasun seinale apoptotikoa saihestea. Lan honetako sarreran azaldu dugun bezala, NMDA hartzaileek funtsezko papera jokatzen dute istripu zerebrobaskularrak eragindako heriotza neuronal exzitotoxikoan. Hala ere, NMDAR kanalen blokeatzaileek ez dute eraginkortasun terapeutikorik erakutsi istripu zerebrobaskularraren tratamenduan. Horrek hartzaile honen seinaleztapen exzitotoxikoan parte hartzen duten elementuen inhibizioan oinarritutako estrategiak bultzatu ditu. Hala nola, NMDAR hartzaileen gainaktibazioak eragindako NO sintesia bideratzen duen dentsitate postsinaptikoko proteina-95aren (PSD-95) inhibitzaileak nabarmendu dira, IZBaren kontrako etorkizun handiko terapia bezala [5].

Beraz, estrategia edozein delarik ere, gaur egun klinikan erabiltzen diren aukera terapeutiko guztien helburua neuronen heriotza-prozesua galaraztea da, IZBen ondorioz gertatzen den kalte neurologikoa gutxitzeko. Tamalez, asaldura izandako gunean odol-fluxua berreskuratzen duten edota neurobabesean oinarritzen diren tratamenduak erabilita ere, asko dira itzulezinak diren kalte neurologikoak pairatzen dituzten gaixoak. Hori dela eta, paziente hauen egoera klinikoa hobetzeko asmoz, galdutako zirkuitu neuronalak berrezartzeko estrategiak bilatzen dituzten ikerkuntza-lerro berri asko garatzen ari dira. Horren adibide nagusia terapia zelularra da. 


\section{TERAPIA ZELULARRA IZB-ean}

IZB izandako paziente kroniko askok dauzkaten funtzio neurologikoen galerei aurre egiteko, terapia zelularrean oinarritutako bi tratamendu-lerro berri sortu dira: terapia zelular endogenoa eta exogenoa. Estrategia endogenoa, gaixoak berak dauzkan zelula ama neuronalen mobilizazioan, biziraupena luzatzean eta ekoizpena bultzatzean datza. Exogenoan, aldiz, gaixoari kanpo-iturri batetik lortutako zelula neuronalak transplantatzen zaizkio.

\subsection{Terapia zelular endogenoa}

Orain dela urte gutxi arte, neuronek birsortzeko gaitasunik ez zutela pentsatzen zen. Hala ere, NSZko neurona heldu gehienek mitosia egiteko ahalmenik ez dutela egia izan arren, garuneko zenbait gunetan (adibidez, hipokanpoko hortz-bihurgunean), neuronak garapeneko egoera zehatzetan bikoizteko gaitasuna dutela deskribatu da garapeneko egoera zehatzetan [20-23]. Bestetik, garuneko gune batzuetan, zelula ama neuronalak (NSC) daude eta haien aktibazioa eta migrazioa dela medio, neurona berriak sortzen dira $[24,25]$. NSC zelulak batez ere eremu subentrikularrean [26] eta hipokanpoko hortz-bihurguneko geruza subgranularrean [27, 28] daude. Are gehiago, kalte neurologikoen ondoren zelula ama hauen proliferazio-, desberdintze- eta migrazio-prozesuak bultzatzen direla deskribatu da $[29,30]$.

Aurkikuntza horietan oinarrituta, IZB izandako gaixoen tratamendurako estrategia berrien bilaketan, ikerketa-taldeek gaixoen garuneko NSC zelulen proliferazioan eta desberdintze-tratamenduen garapenean lan egiten dute [31,32]. Entseatutako tratamendu terapeutikoen artean, honako hauek erabili dira: gliatik eratorritako faktore neurotrofikoa, garunetik eratorritako faktore neurotrofikoa, odol-hodietako endotelioaren hazkuntza-faktorea (VEGF), eritropoietina eta farmako antiinflamatorioak [33-42].

Dena dela, NSC zelulen proliferazioa bultzatzen duten metodoek izan dezaketen arrisku tumorigenikoa dela eta, eztabaidan dago haien erabilera terapeutikoa.

\subsection{Terapia zelular exogenoa}

Aipatu dugunez, terapia zelular exogenoa gaixoaren gorputzetik kanpo lortutako zelula neuronalen transplantean datza. Horretarako, aztertu den neurona-iturri nagusia fetu jatorria duten neurona primarioak dira, baina, arazo etikoak direla eta, neuronen iturri berrien bila dihardu komunitate zientifikoak. Nagusiki, hiru dira gaur egun probatzen ari diren zelula neuronalen iturri berriak: zelula ama enbrionarioetatik eratorritako zelula neu- 
Teratokartzinometatik eratorritako zelula-lerro neuronalen (NT2N) transplantea: istripu zerebrobaskularra izandako gaixo kronikoentzako estrategia terapeutiko berria

ronalen aitzindariak (NPC), ehun helduetatik eratorritakoak (NSC) eta zelula-lerro hilezkorrak (1. irudia).
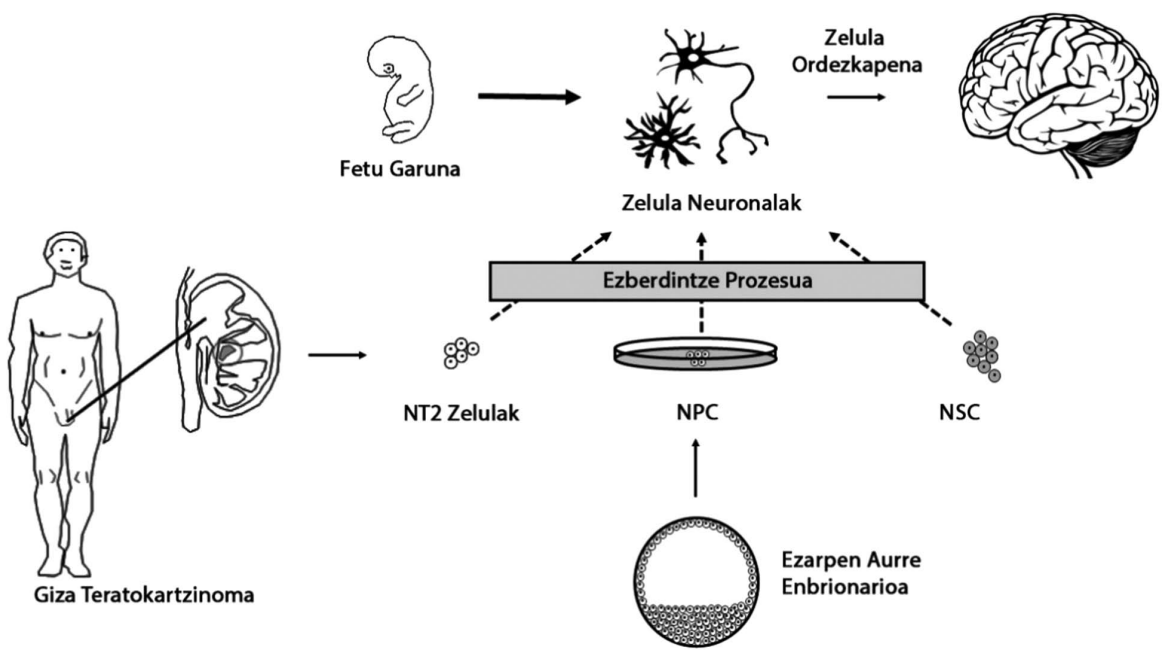

1. irudia. Terapia zelular exogenorako erabil daitezkeen zelula neuronalen iturriak. Donovan eta Gearhart (2001)-etik moldatua [64].

Zelula ama enbrionarioak pluripotenteak dira, hau da, era jarraian bikoiztu eta organismoko edozein ehunetako zeluletan bereizi daitezke. Hala ere, fetu jatorria duten neurona primarioak bezala, arazo etikoengatik, zelula ama enbrionarioen erabilera mugatuta dago. Horrez gain, haien proliferazio-ahalmen altua dela eta, tumoreak garatzeko arriskua egongo litzateke.

Zelula neuronalak lortzeko dagoen bigarren aukera zelula ama helduak erabiltzea da. Lehen aipatu dugunez, gorputzeko ehun heldu mota ugari birsor daitezke ehun horietan dauden zelula amei esker. Zelula ama helduak multipotenteak dira, hau da, haien jatorri enbrionarioaren arabera ehun mota mugatu batzuetara bereiz daitezke, esaterako, jatorri mesodermikoa duten zelula ama helduak soilik jatorri mesodermikoa duten ehun bilaka daitezke. Beraz, aurretik azaldutako zelula ama enbrionarioekin alderatuta, hauek desberdintze- eta bikoizte-ahalmen txikiagoa daukate. Ehun helduetatik eratorritako zelula neuronalen iturri desberdinen artean, gaur egun ikerkuntza gehienetan erabiltzen direnak hezur-muinetik eratorritako zelula ama mesenkimalak dira. Zelula horiek, in vitro, neuronekin batera ko-kulturan haztean, neurona fenotipo ezberdinetan bereizten direla ikusi da. Gainera, iskemia-ereduetan, hezur-muinetik eratorritako zelula ama horiek ahalmen neurobabeslea, antiinflamatorioa, neurogenikoa eta angiogenikoa dutela deskribatu da [43]. 
Amaia Isasti, Imanol Gonzalez-Burguera, Leire Borrega, Miquel Saumell, Sergio Barrondo, Joan Sallés, Gontzal García del Caño, Maider López de Jesús

Azkenik, zelula-lerro hilezkorrak, tumore zeluletatik edo manipulazio genetikotik lortzen diren zelulak dira. Zelula-lerro horiek hainbat fenotipo zelularretara, neuronala barne, bereizteko gai dira. Zelula-lerro hilezkorren erabileraren abantailen artean, arazo etikorik eza, ia mugagabeko eta berehalako erabilgarritasuna, eta beharren arabera biologia zelular zein molekularreko estrategiekin genetikoki eraldatzeko aukera izatea dira. Arrazoi horiengatik guztiengatik, zelula-lerro hilezkorrek nerbio-sistema zentraleko gaixotasunen tratamendurako erabilera potentzial izugarria dutela uste da $[44,45]$.

Zelula mota haien artean, giza teratokartzinomatik eratorritako enbrioikartzinomako zelula-lerroa (Ntera2/D1 edo NT2) aurkitzen da. NT2 zelulak, azido erretinoikoarekin edo Citosina- $\beta$-D-arabinofuranosido (AraC) mitosi inhibitzailearekin tratatuz, NT2N izeneko zelula neuronalak lortzen dira $[46,47]$.

\section{NT2N ZELULEN TRASPLANTEA}

\subsection{NT2N eredu neuronala}

Giza enbrioi kartzinoman jatorria duten Ntera2/D1 (NT2) zelulak azido erretinoikorekin (RA/NT2N) edo AraCrekin (AraC/NT2N) tratatuz lortzen da NT2N eredu neuronala $[46,47]$. NT2 zelula tratatu gabeek, zelula epitelialen aitzindarien ezaugarriak dituzte, baina tratamenduaren ostean, ezaugarri horiek galdu eta neurona izaera hartzen dute [47-49].

Horrela, ezberdintze-prozesua amaitzean, NT2ak zelula postmitotiko bilakatzen dira (NT2N). Hau da, tratamenduaren osteko NT2N zelulek ez dute bikoizteko gaitasunik, eta gainera, lortutako izaera neuronala epe luzean mantentzen dute. Hortaz, behin ezberdinduta, NT2N zelulek egoera neoplasikora itzultzeko gaitasuna galtzen dute eta, haien erabilerak ez luke arrisku tumorigenikorik izango tratamendu terapeutiko gisa [49].

Egin diren ikerketetan, ondo aztertu dira NT2N zelula neuronalen ezaugarriak, maila morfologikoan, biokimikoan eta funtzionalean,. Hasteko, NT2 zelula-lerrotik eratorritako NT2N zelulen azterketa morfologikoan, zelula horiek neuronen oinarrizko ezaugarriak dituztela deskribatu da. Bi luzakin mota bereizi daitezke: zelularen gorputzetik irteten diren luzakin luze eta estuak (axoi itxurakoak) eta oinarri lodiagoa duten eta mehetuz eta adarkatuz doazen beste batzuk (dendrita itxurakoak) [47]. Gainera, ezberdintze-tratamenduaren arabera, neurotransmisore fenotipo desberdina garatzen dute. Horrela, ezaugarri morfologiko eta biokimikoei begira, deskribatu da RA/NT2Nek fenotipo GABAergikodun neuronen ezaugarriak dituztela eta, aldiz, AraC/NT2N zelulek fenotipo glutamatergiko/kolinergikodun neuronen ezaugarriak dituztela $[50,51]$. Halaber, ikerketa elektrofi- 
Teratokartzinometatik eratorritako zelula-lerro neuronalen (NT2N) transplantea: istripu zerebrobaskularra izandako gaixo kronikoentzako estrategia terapeutiko berria

siologikoen bitartez, RA/NT2N neuronak elkarren arteko konexio funtzionalak sortzeko gai direla frogatu da $[52,53]$.

Laburbilduz, in vitro ikerketen arabera, NT2Nak ezaugarri morfologiko eta biokimiko neuronala izateaz gain, elkarren arteko konexioak sortzeko eta sinapsi funtzionalak garatzeko gai dira.

\subsection{NT2N zelulen transplantea}

Aurreko atalean deskribatu diren ezaugarriek argi adierazten dute NT2N zelulek duten izaera neuronala. Hori dela eta, azken urteotan, ikerketa-talde asko iktusa izandako pazienteetan NT2N zelulen transplanteen erabilgarritasuna aztertzen ari dira. Estrategia terapeutiko berri horren segurtasuna eta eraginkortasuna ikertzeko asmoz, animalia-ereduetan (entsegu preklinikoak) zein gizakietan (entsegu klinikoak) lehenengo entseguak egiten hasi dira.

Karraskariekin egindako lehen ikerketek, NSZean inokulatzean, frogatu zuten NT2N zelulak epe luzez bizirik iraun zutela, heltze-prozesuari jarraitu ziotela, eta gainera, nerbio-sisteman integratzen zirela [54, 55]. Behin NSZean ondo integratzen zirela ikusita, NT2Nak patologien ondorioz hil edo galdu diren neuronak ordezkatzeko gai diren aztertzeko, IZB iskemikodun animalia-ereduak erabili ziren. Animalia horiekin egindako azterketetan, NT2Nen transplanteak animalien funtzio motorean zein kognitiboan hobekuntzak eragiten zituela deskribatu zen [56-58]. Tratamenduaren segurtasunari dagokionez, transplantatutako NT2N zelulak epe luzera egoera neoplasikora itzultzen ez zirela, eta, beraz, haien erabilera terapeutiko potentzialak arrisku tumorigenikorik ez zuela frogatu zen $[59,60]$.

Arratoiekin segurtasun- zein eraginkortasun-mailan lortutako emaitza baikorretan oinarrituta, iktusa izandako pazienteekin lehenengo entseguak egin dira. Lehen entsegu klinikoa 2000. urtean egin zen. Entsegu haren helburu nagusia NT2N mentuaren bideragarritasuna eta segurtasuna aztertzea zen. Gongoil basaletako IZB iskemikoa eta funtzio motorearen gutxiagotze egonkorra zuten paziente guztiei NT2N zelulen transplantean oinarritutako tratamendu bera ezarri zitzaien. Pazienteei NT2N zelulak inokulatu zizkieten iktusa gertatutako lekuan, eta mentuaren errefusa saihesteko 9 astean zehar ziklosporina immunokentzailearekin tratatu zituzten. Ondoren, tratamendu berriaren segurtasun-profila aztertzeko asmoz, urtebeteko jarraipena egin zitzaien [61]. Emaitzei dagokienez, mentuaren ezarpena arazorik gabe egin zen paziente guztietan, eta ez zen antzeman neurona mentuarekin erlazionaturiko nahigabeko eraginik. Halaber, aipatutako entseguan zein antzeko diseinuarekin gizakietan egindako beste entsegu batzuetan ere, transplantatutako zelulek epe luzera bizirauten zutela eta beren egoera postmitotikoa mantentzen zutela frogatu zen $[61,62]$. 
Amaia Isasti, Imanol Gonzalez-Burguera, Leire Borrega, Miquel Saumell, Sergio Barrondo, Joan Sallés, Gontzal García del Caño, Maider López de Jesús

Bestalde, entsegu mota hauen diseinua eraginkortasunari buruzko ondorio esanguratsurik lortzeko egokia ez izan arren (gaixo guztiek tratamendu bera hartzen zutenez, ez zegoen konparaketa-talderik), transplantea jasotako gaixo batzuetan, funtzio motorea aztertzeko erabiltzen diren ohiko eskalen arabera, hobekuntza klinikoak deskribatu ziren [61].

Kondziolka ikertzaileak zuzendutako ikerkuntza-taldeak burututako lehenengo entsegu honek NT2N zelulen transplantearen segurtasuna frogatu eta eraginkortasunaren lehenengo zeharkako emaitzak lortu ostean, ikerketa-talde berak, gaixo kopuru handiagoarekin, tratamenduaren segurtasuna berresteko eta, batez ere, eraginkortasuna aztertzeko asmoz, bigarren entsegu bat garatu zuen. Entseguan, berriz ere, NT2N zelulen transplantea gongoil basaletako iktus iskemikoa edo hemorragikoa izan zuten, eta asaldura motoreak zeuzkaten pazienteetan egin zen. Oraingo honetan helburua eraginkortasuna aztertzea zenez, pazienteak bi talde nagusitan banatu zituzten. Lehenengo taldeko gaixoek transplante zelularra eta bi hilabeteko errehabilitazioa jaso zuten, eta bigarren taldekoek (konparaketa-taldea), aldiz, errehabilitazioa soilik. Kirurgia-egunetik hasita, bi tratamenduen eraginkortasuna neurtzeko asmoz, urtebeteko segimendua egin zitzaien gaixo guztiei [63].

Entseguaren ostean lortutako segurtasunaren inguruko datuei dagokienez, oro har mentuen txertaketa ondo burutu zen, eta ez zen funtzio neurologikoen galera berririk izan. Gainera, ez zen beste eragin desiragaitzik hauteman epe luzera, eta lehenengo entseguarekin frogatutako NT2Nen transplanteen segurtasuna berretsi zen. Eraginkortasunari dagokionez, errehabilitazioa soilik jasotako pazienteekin alderatuta, NT2N zelulen inokulazioa jasandakoek, aipatutako eskalen arabera, hobekuntza-maila handiagoa izan zuten. Dena dela, neurtutako ezberdintasun hauek ez ziren estatistikoki esanguratsuak izan. Ikertzaileen arabera, emaitza negatiboak lortzea laginaren tamaina txikiak, entseguaren iraupen laburrak edo gaixoen etiologia heterogeneoak azalduko luke [63].

\section{ONDORIOAK}

IZB izandako gaixo kronikoek pairatzen duten funtzio neurologikoen galeraren tratamendurako, terapia zelular exogenoa etorkizuneko aukera terapeutikoa bilaka daiteke. Neuronen iturri desberdinen artean, zelula-lerro hilezkorrak dira, arrazoi etiko zein praktikoak kontuan hartuz, abantaila gehien dituztenak. Orain arte, animalietan zein gizakietan egindako entseguetan, talde honetan leudekeen NT2N eredu neuronalak segurtasun-profil egokia eta nolabaiteko eraginkortasuna duela frogatu dute. Beraz, terapia berri hau eraginkorra dela egiaztatzeko eta epe luzera segurua dela frogatzeko entsegu gehiago egitea ezinbestekoa den arren, artikulu honetan be- 
Teratokartzinometatik eratorritako zelula-lerro neuronalen (NT2N) transplantea: istripu zerebrobaskularra izandako gaixo kronikoentzako estrategia terapeutiko berria

rrikusitako emaitzek iradokitzen dute IZB izandako gaixoentzat terapia zelularra etorkizun handiko estrategia terapeutikoa izan daitekeela.

\section{BIBLIOGRAFIA}

[1] PÉrez, A. R. 2004. Rey, A., Emergencias Neurológicas (C2005 Últ. Reimpr. 2006. Masson.

[2] WISE, R. J. S., BERNARDI, S., FRACKOWIAK, R. S. J., LEGG, N. J., JONES, T. 1983. «Serial observations on the pathophysiology of acute stroke: the transition from ischaemia to infarction as reflected in regional oxygen extraction». Brain, 106, 197-222.

[3] Garcia, J. H., Khang-Loon, H., Pantoni, L. 1998. «Pathology in Barnett, Henry JM, Mohr JP, Stein BM, Yastu FM». Stroke Pathophysiology, Diagnosis and Management. Third edition, Philadelphia, PA: Churchill Livingstone.

[4] Deb, P., Sharma, S., Hassan, K. M. 2010. «Pathophysiologic mechanisms of acute ischemic stroke: An overview with emphasis on therapeutic significance beyond thrombolysis». Pathophysiology, DOI: 10.1016/j. pathophys.2009.12.001.

[5] Wu, Q. J., Tymianski, M. 2018. «Targeting nmda receptors in stroke: New hope in neuroprotection Tim Bliss». Molecular Brain, 11, 1-14.

[6] Manning, E. E., Ransome, M. I., Burrows, E. L., Hannan, A. J. 2012. «Increased adult hippocampal neurogenesis and abnormal migration of adultborn granule neurons is associated with hippocampal-specific cognitive deficits in phospholipase C- $\beta 1$ knockout mice». Hippocampus, 22, 309-319.

[7] Bose P, Hou J, T. F.in: FH, K. (Ed.), Brain Neurotrauma: Molecular, Neuropsychological, and Rehabilitation Aspects. CRC Press/Taylor \& Francis, Boca Raton (FL) 2015.

[8] Faraveldi, I., CorTI, S. 2018. «MicroRNA-Directed Neuronal Reprogramming as a Therapeutic Strategy for Neurological Diseases». Molecular Neurobiology, 55, 4428-4436.

[9] Tsintou, M., Dalamagkas, K., Seifalian, A. 2015. «Advances in regenerative therapies for spinal cord injury: a biomaterials approach». Neural Regeneration Research, 10, 726-742.

[10] Khazaei, M., Ahuja, C. S., Fehlings, M. G. 2017. «Induced Pluripotent Stem Cells for Traumatic Spinal Cord Injury ». Frontiers in Cell and Developmental Biology, 4, 152.

[11] Kim, C.-Y., Wang, K.-C., Kim, S.-K., Chung, Y.-N., Kim, H.-S., Cho, B.-K. 2003. «Encephaloduroarteriosynangiosis with bifrontal encephalogaleo (periosteal) synangiosis in the pediatric moyamoya disease: the surgical technique and its outcomes». Child's Nervous System, 19, 316-324.

[12] Lynch, J. K. 2004. «Cerebrovascular disorders in children». Current neurology and neuroscience reports, 4, 129-138. 
[13] Saver, J. L., Gornbein, J., Grotta, J., Liebeskind, D., Lutsep, H., Schwamm, L., Scott, P., Starkman, S. 2009. «Number needed to treat to benefit and to harm for intravenous tissue plasminogen activator therapy in the 3-to 4.5-hour window: joint outcome table analysis of the ECASS 3 trial». Stroke, 40, 2433-2437.

[14] Lyden, P. D., Allgren, R. L., NG, K., Akins, P., Meyer, B., Al-Sanani, F., Lutsep, H., DobaK, J., Matsubara, B. S., Zivin, J. 2005. «Intravascular Cooling in the Treatment of Stroke (ICTuS): early clinical experience». Journal of Stroke and Cerebrovascular Diseases, 14, 107-114.

[15] Powers, W. J., Rabinstein, A. A., Ackerson, T., Adeoye, O. M., Bambakidis, N. C., Becker, K., Biller, J., Brown, M., Demaerschalk, B. M., Hoh, B., Jauch, E. C., Kidwell, C. S., Leslie-Mazwi, T. M., Ovbiagele, B., Scott, P. A., Sheth, K. N., Southerland, A. M., Summers, D. V., Tirschwell, D. L. 2019. «Guidelines for the Early Management of Patients With Acute Ischemic Stroke: 2019 Update to the 2018 Guidelines for the Early Management of Acute Ischemic Stroke: A Guideline for Healthcare Professionals From the American Heart Association/American Stroke». Stroke, 50, e344-e418.

[16] Pitronen, K., Tiainen, M., Mustanoja, S., Kaukonen, K.-M., Meretoja, A., TATLisumaK, T., KASte, M. 2014. «Mild hypothermia after intravenous thrombolysis in patients with acute stroke: a randomized controlled trial». Stroke, 45, 486-491.

[17] Hill, M. D., Martin, R. H., Mikulis, D., Wong, J. H., Silver, F. L., Milot, G., Clark, W. M., MacDonald, R. L., Kelly, M. E., Boulton, M. 2012. «Safety and efficacy of NA-1 in patients with iatrogenic stroke after endovascular aneurysm repair (ENACT): a phase 2, randomised, double-blind, placebo-controlled trial». The Lancet Neurology, 11, 942-950.

[18] Investigators, I. I. T. 2007. «The interventional management of stroke (IMS) II study». Stroke, 38, 2127-2135.

[19] Bernard, S. A., Buist, M. 2003. «Induced hypothermia in critical care medicine: a review». Critical care medicine, 31, 2041-2051.

[20] Boldrini, M., Fulmore, C. A., Tartt, A. N., Simeon, L. R., Pavlova, I., Poposka, V., Rosoklija, G. B., Stankov, A., Arango, V., Dwork, A. J. 2018. «Human hippocampal neurogenesis persists throughout aging». Cell stem cell, 22, 589-599.

[21] Sorrells, S. F., Paredes, M. F., Cebrian-Silla, A., Sandoval, K., Qi, D., Kelley, K. W., James, D., Mayer, S., Chang, J., Auguste, K. I. 2018. «Human hippocampal neurogenesis drops sharply in children to undetectable levels in adults». Nature, 555, 377 .

[22] Aranda-AnZaldo, A. 2012. «The post-mitotic state in neurons correlates with a stable nuclear higher-order structure». Communicative \& integrative biology, 5, 134-139.

[23] AndreaE, L. C. 2018. «Adult neurogenesis in humans: Dogma overturned, again and again?». Science Translational Medicine, 10, eaat3893. 
Teratokartzinometatik eratorritako zelula-lerro neuronalen (NT2N) transplantea: istripu zerebrobaskularra izandako gaixo kronikoentzako estrategia terapeutiko berria

[24] Altman, J. 1962. «Are new neurons formed in the brains of adult mammals?». Science, 135, 1127-1128.

[25] Paton, J. A., O’Loughlin, B. E., Nottebohm, F. 1985. «Cells born in adult canary forebrain are local interneurons». Journal of Neuroscience, 5, 3088-3093.

[26] Goldman, S. A., Notтевонм, F. 1983. «Neuronal production, migration, and differentiation in a vocal control nucleus of the adult female canary brain». Proceedings of the National Academy of Sciences, 80, 2390-2394.

[27] ANDERSON, D. J. 2001. «Stem cells and pattern formation in the nervous system: the possible versus the actual». Neuron, 30, 19-35.

[28] Doetsch, F., Petreanu, L., Caille, I., Garcia-Verdugo, J.-M., AlvarezBuYLLA, A. 2002. «EGF converts transit-amplifying neurogenic precursors in the adult brain into multipotent stem cells». Neuron, 36, 1021-1034.

[29] Goings, G. E., SAhni, V., Szele, F. G. 2004. «Migration patterns of subventricular zone cells in adult mice change after cerebral cortex injury». Brain research, 996, 213-226.

[30] Parent, J. M., Vexler, Z. S., Gong, C., Derugin, N., Ferriero, D. M. 2002. «Rat forebrain neurogenesis and striatal neuron replacement after focal stroke». Annals of Neurology: Official Journal of the American Neurological Association and the Child Neurology Society, 52, 802-813.

[31] Dempsey, R. J., Sailor, K. A., Bowen, K. K., Türeyen, K., Vemuganti, R. 2003. «Stroke-induced progenitor cell proliferation in adult spontaneously hypertensive rat brain: effect of exogenous IGF-1 and GDNF». Journal of neurochemistry, 87, 586-597.

[32] Kobayashi, T., Ahlenius, H., Thored, P., Kobayashi, R., Kokaia, Z., LindVALL, O. 2006. "Intracerebral infusion of glial cell line-derived neurotrophic factor promotes striatal neurogenesis after stroke in adult rats». Stroke, 37, 2361-2367.

[33] Chou, J., Harvey, B. K., Chang, C.-F., Shen, H., Morales, M., Wang, Y. 2006. «Neuroregenerative effects of BMP7 after stroke in rats». Journal of the neurological sciences, 240, 21-29.

[34] Guerra-Crespo, M., Gleason, D., Sistos, A., Toosky, T., Solaroglu, I., Zhang, J. H., Bryant, P. J., FAllon, J. H. 2009. «Transforming growth factor-alpha induces neurogenesis and behavioral improvement in a chronic stroke model». Neuroscience, 160, 470-483.

[35] Jin, K., Zhu, Y., Sun, Y., MaO, X. O., XIE, L., Greenberg, D. A. 2002. «Vascular endothelial growth factor (VEGF) stimulates neurogenesis in vitro and in vivo». Proceedings of the National Academy of Sciences, 99, 11946-11950.

[36] Lee, S.-R., Kim, H.-Y., Rogowska, J., Zhao, B.-Q., Bhide, P., Parent, J. M., Lo, E. H. 2006. «Involvement of matrix metalloproteinase in neuroblast cell migration from the subventricular zone after stroke». Journal of Neuroscience, 26, 3491-3495.

[37] Leker, R. R., Soldner, F., Velasco, I., Gavin, D. K., AndroutsellisTheotokis, A., McKay, R. D. 2007. «Long-lasting regeneration after ischemia in the cerebral cortex». Stroke, 38, 153-161. 
[38] Popa-Wagner, A., Stöcker, K., Balseanu, A. T., Rogalewski, A., DiedeRich, K., Minnerup, J., Margaritescu, C., SchäBitZ, W.-R. 2010. «Effects of granulocyte-colony stimulating factor after stroke in aged rats». Stroke, 41, 1027-1031.

[39] Sairanen, M., Lucas, G., Ernfors, P., Castrén, M., Castrén, E. 2005. «Brain-derived neurotrophic factor and antidepressant drugs have different but coordinated effects on neuronal turnover, proliferation, and survival in the adult dentate gyrus». Journal of Neuroscience, 25, 1089-1094.

[40] Schneider, A., Krüger, C., Steigleder, T., Weber, D., Pitzer, C., LaAge, R., Aronowski, J., Maurer, M. H., Gassler, N., Mier, W. 2005. «The hematopoietic factor G-CSF is a neuronal ligand that counteracts programmed cell death and drives neurogenesis». The Journal of clinical investigation, 115, 2083-2098.

[41] Teramoto, T., Qiu, J., Plumier, J.-C., Moskowitz, M. A. 2003. «EGF amplifies the replacement of parvalbumin-expressing striatal interneurons after ischemia». The Journal of clinical investigation, 111, 1125-1132.

[42] Wittko, I. M., Schänzer, A., Kuzmichev, A., Schneider, F. T., Shibuya, M., RAAB, S., PlAte, K. H. 2009. «VEGFR-1 regulates adult olfactory bulb neurogenesis and migration of neural progenitors in the rostral migratory stream in vivo». Journal of Neuroscience, 29, 8704-8714.

[43] Bhatt, V. R., Balasetti, V., Jasem, J. A., Giri, S., Armitage, J. O., LoBeriza Jr, F. R., Bociek, R. G., Bierman, P. J., Maness, L. J., Vose, J. M. 2015. «Central nervous system complications and outcomes after allogeneic hematopoietic stem cell transplantation». Clinical Lymphoma Myeloma and Leukemia, 15, 606-611.

[44] Anenberg, E., Arstikaitis, P., NitTsu, Y., Harrison, T. C., Boyd, J. D., Hilton, B. J., Tetzlaff, W., Murphy, T. H. 2014. «Ministrokes in channelrhodopsin-2 transgenic mice reveal widespread deficits in motor output despite maintenance of cortical neuronal excitability». Journal of Neuroscience, 34, 1094-1104.

[45] Conforto, A. B., Anjos, S. M., Saposnik, G., Mello, E. A., Nagaya, E. M., Santos, W., Ferreiro, K. N., Melo, E. S., Reis, F. I., Scaff, M. 2012. «Transcranial magnetic stimulation in mild to severe hemiparesis early after stroke: a proof of principle and novel approach to improve motor function». Journal of neurology, 259, 1399-1405.

[46] ANDREWS, P. W. 1984. «Retinoic acid induces neuronal differentiation of a cloned human embryonal carcinoma cell line in vitro». Developmental Biology, 103, 285-293.

[47] Pleasure, S. J., Page, C., Lee, V. M. 1992. «Pure, postmitotic, polarized human neurons derived from NTera 2 cells provide a system for expressing exogenous proteins in terminally differentiated neurons». The Journal of Neuroscience, 12, 1802 LP-1815.

[48] LeE, V. M., ANDrEws, P. W. 1986. «Differentiation of NTERA-2 clonal human embryonal carcinoma cells into neurons involves the induction of all three neurofilament proteins». The Journal of Neuroscience, 6, 514 LP-521. 
Teratokartzinometatik eratorritako zelula-lerro neuronalen (NT2N) transplantea: istripu zerebrobaskularra izandako gaixo kronikoentzako estrategia terapeutiko berria

[49] Pleasure, S. J., Lee, V. M.-Y. 1993. «NTera 2 Cells: A human cell line which displays characteristics expected of a human committed neuronal progenitor cell». Journal of Neuroscience Research, 35, 585-602.

[50] GonzÁlez-Burguera, I., Ricobaraza, A., AretXabala, X., Barrondo, S., García del CaÑo, G., LóPez de Jesús, M., Sallés, J. 2016. «Highly efficient generation of glutamatergic/cholinergic NT2-derived postmitotic human neurons by short-term treatment with the nucleoside analogue cytosine $\beta$-d-arabinofuranoside». Stem Cell Research, 16, 541-551.

[51] González-Burguera, I., Ricobaraza, A., AretXabala, X., Barrondo, S., García del Caño, G., López de Jesús, M., Sallés, J. 2016. «Data for the morphometric characterization of NT2-derived postmitotic neurons». Data in Brief, 7, 1349-1354.

[52] Hartley, R. S., Margulis, M., Fishman, P. S., Lee, V. M.-Y., Tang, C.-M. 1999. «Functional synapses are formed between human NTera2 (NT2N, hNT) neurons grown on astrocytes». Journal of Comparative Neurology, 407, 1-10.

[53] Podrygajlo, G., Song, Y., Schlesinger, F., Krampfl, K., Bicker, G. 2010. «Synaptic currents and transmitter responses in human NT2 neurons differentiated in aggregate culture». Neuroscience Letters, 468, 207-210.

[54] Trojanowski, J. Q., Mantione, J. R., Lee, J. H., Seid, D. P., You, T., Inge, L. J., LEE, V. M.-Y. 1993. «Neurons derived from a human teratocarcinoma cell line establish molecular and structural polarity following transplantation into the rodent brain». Experimental Neurology, 122, 283-294.

[55] Hara, K., Matsukawa, N., Yasuhara, T., Xu, L., Yu, G., Maki, M., Kawase, T., Hess, D. C., KIM, S. U., Borlongan, C. V. 2007. «Transplantation of post-mitotic human neuroteratocarcinoma-overexpressing Nurr1 cells provides therapeutic benefits in experimental stroke: In vitro evidence of expedited neuronal differentiation and GDNF secretion». Journal of Neuroscience Research, 85, 1240-1251.

[56] Borlongan, C. V, Saporta, S., Poulos, S. G., Othberg, A., Sanberg, P. R. 1998. «Viability and survival of hNT neurons determine degree of functional recovery in grafted ischemic rats». NeuroReport, 9.

[57] Borlongan, C. V, Tajima, Y., Trojanowski, J. Q., LeE, V. M.-Y., SanBERG, P. R. 1998. «Cerebral ischemia and CNS transplantation: differential effects of grafted fetal rat striatal cells and human neurons derived from a clonal cell line». NeuroReport, 9.

[58] Philips, M. F., Muir, J. K., Saatman, K. E., Raghupathi, R., Lee, V. M.-Y., Trojanowski, J. Q., McIntosh, T. K. 1999. «Survival and integration of transplanted postmitotic human neurons following experimental brain injury in immunocompetent rats». Journal of Neurosurgery, 90, 116-124.

[59] Borlongan, C. V., Tajima, Y., Trojanowski, J. Q., Lee, V. M.-Y., SanBERG, P. R. 1998. «Transplantation of Cryopreserved Human Embryonal Carcinoma-Derived Neurons (NT2N Cells) Promotes Functional Recovery in Ischemic Rats». Experimental Neurology, 149, 310-321. 
Amaia Isasti, Imanol Gonzalez-Burguera, Leire Borrega, Miquel Saumell, Sergio Barrondo, Joan Sallés, Gontzal García del Caño, Maider López de Jesús

[60] Bliss, T. M., Kelly, S., Shah, A. K., Foo, W. C., Kohli, P., Stokes, C., Sun, G. H., Ma, M., Masel, J., Kleppner, S. R., Schallert, T., Palmer, T., SteinberG, G. K. 2006. «Transplantation of hNT neurons into the ischemic cortex: Cell survival and effect on sensorimotor behavior». Journal of Neuroscience Research, 83, 1004-1014.

[61] Kondziolka, D., Wechsler, L., Goldstein, S., Meltzer, C., Thulborn, K. R., Gebel, J., Jannetta, P., DeCesare, S., Elder, E. M., McGrogan, M., Reitman, M. A., Bynum, L. 2000. «Transplantation of cultured human neuronal cells for patients with stroke». Neurology, 55, 565 LP-569.

[62] Nelson, P. T., Kondziolka, D., Wechsler, L., Goldstein, S., Gebel, J., DeCesare, S., Elder, E. M., Zhang, P. J., Jacobs, A., McGrogan, M., LeE, V. M.-Y., Trojanowski, J. Q. 2002. «Clonal Human (hNT) Neuron Grafts for Stroke Therapy: Neuropathology in a Patient 27 Months after Implantation». The American Journal of Pathology, 160, 1201-1206.

[63] Kondziolka, D., Steinberg, G. K., Wechsler, L., Meltzer, C. C., Elder, E., Gebel, J., DeCesare, S., Jovin, T., Zafonte, R., Lebowitz, J., FlickinGer, J. C., Tong, D., Marks, M. P., Jamieson, C., LuU, D., Bell-Stephens, T., TeraOKA, J. 2005. «Neurotransplantation for patients with subcortical motor stroke: a Phase 2 randomized trial». Journal of Neurosurgery, 103, $38-45$.

[64] Donovan, P. J., Gearhart, J. 2001. «The end of the beginning for pluripotent stem cells». Nature, 414, 92. 